\title{
Platypnea and orthodeoxia associated with Pneumocystis jiroveci and Cytomegalovirus pneumonia: a case report Konstantinos Katsoulis ${ }^{1}$, Ilias Minasidis' ${ }^{2}$, Andreas Vainas ${ }^{2}$, Christoforos Bikas ${ }^{1}$, Theodoros Kontakiotis*1 and Pantelis Vakianis ${ }^{2}$
}

\author{
Address: ${ }^{2}$ Pulmonary Department, General Army Hospital, Thessaloniki, Greece and ${ }^{2}$ Nephrology Department, General Army Hospital, \\ Thessaloniki, Greece \\ Email: Konstantinos Katsoulis - kfocus@otenet.gr; Ilias Minasidis - ilasminasidis@hotmail.com; Andreas Vainas - anvainas@hol.gr; \\ Christoforos Bikas - pulbikas@otenet.gr; Theodoros Kontakiotis* - kontak@auth.gr; Pantelis Vakianis - nephrol@otenet.gr \\ * Corresponding author
}

Published: 5 December 2009

Journal of Medical Case Reports 2009, 3:9319 doi:10.1186/1752-1947-3-9319

Received: 24 September 2008

Accepted: 5 December 2009

(c) 2009 Katsoulis et al; licensee BioMed Central Ltd.

This is an Open Access article distributed under the terms of the Creative Commons Attribution License (http://creativecommons.org/licenses/by/2.0), which permits unrestricted use, distribution, and reproduction in any medium, provided the original work is properly cited.

\begin{abstract}
Introduction: Platypnea-orthodeoxia is an uncommon syndrome characterized by dyspnea and deoxygenation accompanying a change to a sitting or standing posture from a recumbent position. It is usually related to interatrial communications, although several other disorders associated with platypnea-orthodeoxia syndrome have been reported. However, the precise mechanisms are unknown.
\end{abstract}

Case presentation: We present the case of a 75-year-old Caucasian woman with chronic renal failure due to vasculitis who was admitted with fever and respiratory failure. She was found to have both Pneumocystis jiroveci and Cytomegalovirus pneumonia. She was HIV negative. Severe platypnea and orthodeoxia were major features of her illness with no history of respiratory, liver or cardiac disease. Further investigation with contrast echocardiography revealed no intracardiac or intrapulmonary shunts. Although one case involving Pneumocystis jiroveci pneumonia and platypnea has been previously reported, to the best of our knowledge, this is the first time that two opportunistic pathogens have been accompanied by platypnea and orthodeoxia. As both lung bases were predominantly affected and no obvious explanation was found, platypnea and orthodeoxia were attributed to significant areas of low or zero ventilation/perfusion (V/Q) ratio.

Conclusion: Platypnea-orthodeoxia is a rare and usually underestimated syndrome. Intracardiac shunts and anatomic pulmonary vascular shunts are the most common etiologic associations. However, if a detailed examination reveals no obvious intracardiac or intrapulmonary shunting combined with extensive pulmonary lesions, then severe $\mathrm{V} / \mathrm{Q}$ mismatching should be considered as the probable explanation.

\section{Introduction}

Platypnea-orthodeoxia is a relatively uncommon but striking clinical syndrome characterized by dyspnea and deoxygenation accompanying a change to a sitting or standing posture from a recumbent position. It was first reported in 1949 when Burchell et al. [1] described a patient with an atrial septal defect manifesting platypneaorthodeoxia and subsequently described the reversal of both following closure of a patent foramen ovale. 'Platypnea' and 'orthodeoxia' were not used to describe the man- 
ifestations of this syndrome until they became commonly accepted terms in 1969 and 1976, respectively [2,3]. Since then, a few cases have been reported with interatrial communications being the most common etiologic associations [4-6]. The precise mechanisms for both platypnea and orthodeoxia are unknown. In several isolated case reports, speculation over mechanisms is often geared to whatever special features were found in the patient been reported. We present a case of a patient with severe platypnea and orthodeoxia infected with two opportunistic pathogens and with no evidence of intracardiac or intrapulmonary shunt.

\section{Case presentation}

A 75-year-old Caucasian woman was admitted to our hospital with febrile illness accompanied by dyspnea without other specific symptoms, such as cough or sputum. She was normotensive, and her heart sounds were normal with bibasal lung crepitations. An electrocardiogram demonstrated sinus rhythm with a normal axis and oxygen saturation in room air was $75 \%$. Platypnea and orthodeoxia were major features of her illness. When supine on 35\% oxygen by face mask, arterial blood gas measurements yielded persistent hypoxemia $\left(\mathrm{pO}_{2}: 70 \mathrm{mmHg}, \mathrm{pCO}_{2}: 30\right.$ $\mathrm{mmHg})$ with counterbalanced metabolic acidosis $\left(\mathrm{HCO}_{3}\right.$ : $18 \mathrm{mmol} / \mathrm{l}$, pH 7.44). However, in the upright position, she developed severe hypoxemia $\left(\mathrm{pO}_{2}: 40 \mathrm{mmHg}\right)$. Biochemical tests showed renal failure (urea: $100 \mathrm{mg} / \mathrm{dl}$, creatinine: $2 \mathrm{mg} / \mathrm{dl}$, hematocrit (Hct): 30\%), increased lactate dehydrogenase (LDH) levels $(600 \mathrm{U} / \mathrm{L})$ and increased markers of inflammation (erythrocyte sedimentation rate (ESR): $100 \mathrm{~mm}, \mathrm{CRP}:>100 \mathrm{mg} / \mathrm{dl}$ ), while a chest X-ray showed a few bilateral diffuse interstitial infiltrates, predominantly in the lower lobes.

Five months before admission, oliguric acute renal failure was detected and kidney biopsy revealed rapidly progressive glomerulonephritis with $100 \%$ crescents compatible with Wegener's disease or nodular polyarteritis. She was initially treated with sessions of renal dialysis and plasmapheresis combined with pulses of methylprednisolone. Afterwards, the treatment switched to oral methylprednisolone at $48 \mathrm{mg} /$ day combined with oral cyclophosphamide at $100 \mathrm{mg} /$ day for 2 months with progressive lessening of the doses. Cyclophosphamide was finally withdrawn due to severe side effects (leucopenia). During the last trimester, she was in good condition under treatment with $16 \mathrm{mg} /$ day of methylprednisolone.

She was initially treated with empirical antibiotic treatment and underwent computed tomographic (CT) scanning which showed patchy areas of ground-glass opacity (Figure 1). With the suspicion of Pneumocystis jiroveci pneumonia and despite a negative test for HIV, fiberoptic bronchoscopy and bronchoalveolar lavage (BAL) were

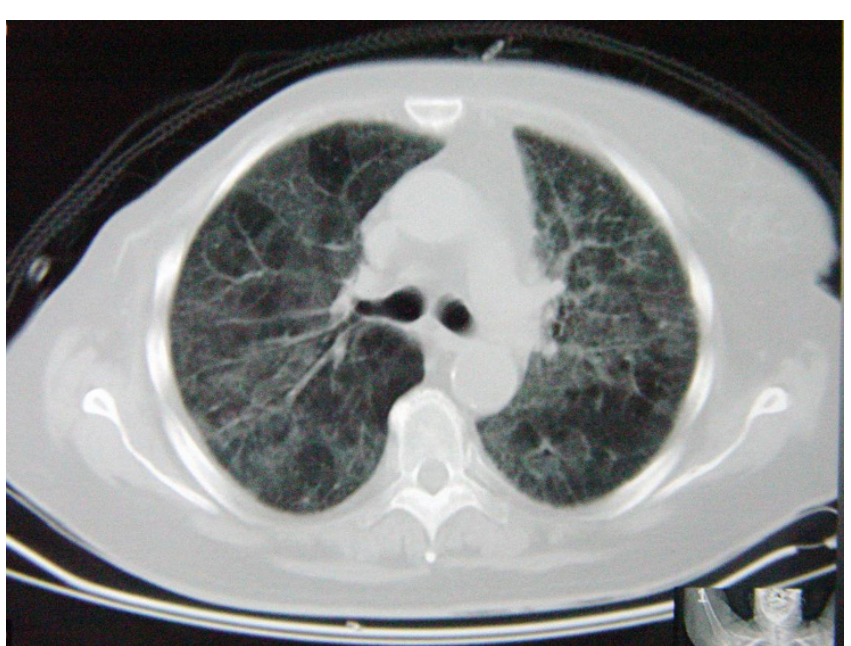

\section{Figure I}

Computed tomography demonstrating patchy areas of ground-glass opacity.

performed. Immunostaining of the specimens was positive for $P$. jiroveci and several cysts were microscopically visualized. Thus, the treatment was changed to high-dose intravenous co-trimoxazole and prednisolone.

Although she became afebrile, the clinical presentation deteriorated with excessive platypnea coupled with orthodeoxia. Sitting up was associated with a fall in her oxygen saturation of up to $67 \%$ under oxygen administration. As there was no evidence of liver disease or hepatopulmonary syndrome, a transthoracic echocardiogram was performed. Intravenously administered normal saline was not detected in the left atrium after two or six cardiac circles excluding the presence of intracardiac or intrapulmonary shunts. Due to the respiratory distress, a pulmonary angiogram was not performed. A new CT scan revealed further deterioration consisting of organized consolidations with air bronchogram at the lung bases and air in the mediastinum (Figure 2). On day 15, she was intubated and admitted to the intensive care unit. At the same time, BAL examination was positive for cytomegalovirus (CMV) through polymerase chain reaction (PCR) (23,000 copies/ $\mathrm{ml}$ ). Intravenous ganciclovir ( $5 \mathrm{mg} / \mathrm{kg}$, twice a day) was added to the treatment. Despite the appropriate treatment, she died on day 25 .

\section{Discussion}

Platypnea (increased dyspnea in the erect position relieved by assuming a recumbent position) and orthodeoxia (accentuated hypoxemia in the erect position, improved by assuming a recumbent position) were the patient's more striking symptoms. Only one case of this syndrome associated with Pneumocystis carinii pneumonia (the old term now replaced by jiroveci) has been previ- 


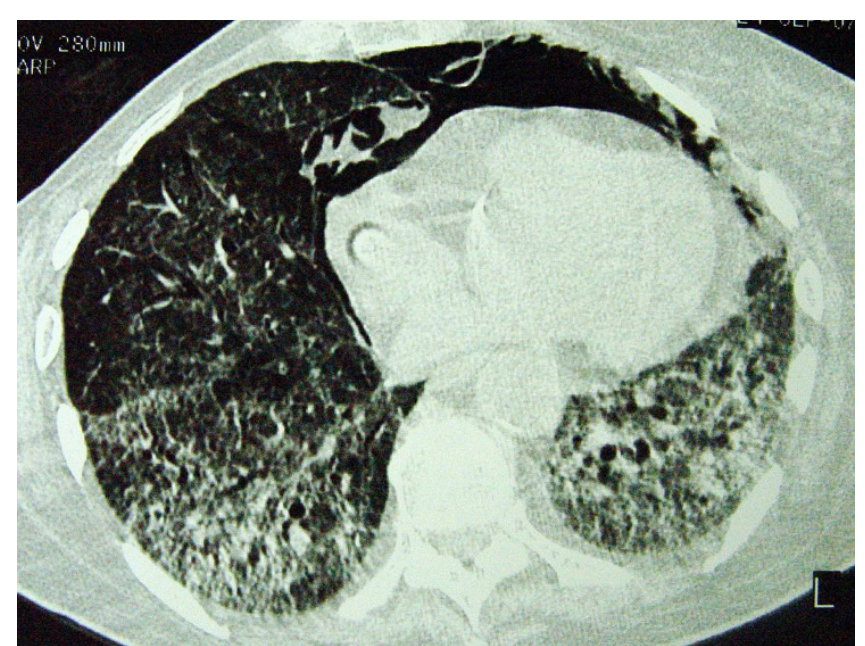

Figure 2

Computed tomography demonstrating organized consolidations with air bronchogram at the lung bases and air in the mediastinum.

ously reported [7]. However, to the best of our knowledge, the association of this syndrome with pulmonary infection by two opportunistic pathogens, including $P$. jiroveci, has not been reported.

The etiologic background of this syndrome includes intracardiac shunts, anatomic pulmonary vascular and pulmonary parenchymal shunts, with interatrial communications being the most common etiologic association, but the precise mechanisms are not known $[5,8,9]$. Other diseases associated with platypnea-orthodeoxia include chronic obstructive pulmonary disease (COPD) [10], constrictive pericarditis [11], pneumonectomy [12], paradoxical embolism [13] and even acute organophosphorus poisoning [14].

In our patient, $P$. jiroveci and CMV were detected in BAL specimens using reliable methods (immunostaining/ microscopic visualization and PCR, respectively) in an immunosuppressed patient. The radiological findings were not diagnostic as both of the above pathogens present with similar findings. It has been noted that coinfection with CMV and other pathogens will be detected in more than half of Pneumocystis-infected patients [15] and thus the major pathogen is not easily defined. As we found no other common pathogens and our patient continued to deteriorate despite the appropriate treatment for $P$. jiroveci pneumonia, we believe that $\mathrm{CMV}$ was responsible for the fatal deterioration.

Our patient had no history or evidence of COPD or chronic liver disease (for example, cirrhosis). As platypnea and orthodeoxia were major features of her illness, further investigation focused on the detection of probable intrac- ardiac or intrapulmonary shunts using contrast echocardiography, a widely accepted and non-invasive method [16]. No evidence of such disorders was found, so these symptoms probably arose as a result of significant areas of low or zero V/Q ratio. Indeed, a CT scan indicated that the lung bases were predominantly affected. Gravity might increase intrapulmonary blood flow shunting through poorly ventilated lung bases exacerbating dyspnea and deoxygenation in the upright position. The same explanation has been proposed by other authors for similar cases $[5,7]$.

Whether specific pathogens such as $P$. jiroveci and/or CMV or severe $\mathrm{V} / \mathrm{Q}$ mismatching of any etiology are responsible for the emergence of this syndrome remains to be clarified.

\section{Conclusion}

Platypnea-orthodeoxia is a rare and usually underestimated syndrome. Intracardiac shunts and particularly, interatrial communications with or without overt lung disease as well as anatomic pulmonary vascular shunts are the most common etiologic associations. However, if detailed examination reveals no obvious intracardiac or intrapulmonary shunting combined with extensive pulmonary lesions, such as severe pneumonia even due to opportunistic pathogens, then severe V/Q mismatching should be considered as the probable explanation.

\section{Abbreviations}

BAL: bronchoalveolar lavage; COPD: chronic obstructive pulmonary disease; CMV: cytomegalovirus; CRP: C-reactive protein; ESR: erythrocyte sedimentation rate; Hct: hematocrit; LDH: lactate dehydrogenase; PCR: polymerase chain reaction; $\mathrm{V} / \mathrm{Q}$ : ventilation/perfusion.

\section{Consent}

Written informed consent was obtained from the patient for publication of this case report and accompanying images. A copy of the written consent is available for review by the Editor-in-Chief of this journal

\section{Competing interests}

The authors declare that they have no competing interests.

\section{Authors' contributions}

KK was the main author and carried out the pulmonary investigation of the case. IM carried out the nephrological investigation of the case. AV carried out vasculitis diagnosis and management of the case. CB carried out the respiratory failure diagnosis and management. TK is the corresponding author and was responsible for manuscript preparation and the pulmonary investigation of the case. PV carried out the renal failure diagnosis and management of the case. 


\section{References}

I. Burchell HB, Hemholz HF Jr, Wood EH: Reflect orthostatic dyspnea associated with pulmonary hypotension. Am J Physiol 1949, I 59:563-564.

2. Altman M, Robin ED: Platypnea (diffuse zone I phenomenon?). N Engl J Med 1969, 28 I: I347-I348.

3. Robin ED, Lamon D, Horn BR, Theodore J: Platypnea related to orthodeoxia caused by true vascular lung shunts. $N$ Engl J Med 1976, 294:94I-943.

4. Seward JB, Hayes DL, Smith HC, Williams DE, Piehler JM, Tajik AJ: Platypnea-orthodeoxia: clinical profile, diagnostic workup, management and report of seven cases. Mayo Clin Proc 1984, 59(4):22I-23I.

5. Robin ED, McCauley F: An analysis of platypnea-orthodeoxia syndrome including a "new" therapeutic approach. Chest |997, I | 2:|449-|45|.

6. Gobart F, Rey C: Platypnea-orthodeoxia syndrome: a probably underestimated syndrome? Chest 200I, I I 9: I624-1625.

7. Newton PN, Wakefield AE, Goldin R, Govan J: Pneumocystis carinii pneumonia with pleurisy, platypnoea and orthodeoxia. Thorax 2003, 58: 185-186.

8. Hagen PT, Scholz DG, Edwards WD: Incidence and size of patent foramen ovale during the first ten decades of life: an autopsy study of 965 normal hearts. Mayo Clin Proc 1984, 59: 17-20.

9. Cheng TO: Mechanisms of platypnea-orthodeoxia: what causes water to flow uphill? Circulation 2002, 105(6):47.

10. Hussain SF, Mekan SF: Platypnea-orthodeoxia: report of two cases and review of the literature. South Med J 2004, 97(7):657-662.

II. Hashimoto M, Okawa Y, Baba H, Nishimura Y, Aoki M: Platypneaorthodeoxia syndrome combined with constrictive pericarditis after coronary artery bypass surgery. J Thorac Cardiovasc Surg 2006, I32(5): I225-1226.

12. Kotoulas C, Patris K, Tsintiris K, Zoumboulides A, Lazarides K, Laoutides G: Platypnea-orthodeoxia syndrome after pneumonectomy relieved by mediastinal repositioning. Ann Thorac Surg 2007, 83(4): I524-1526.

13. Delalieux S, De Greef K, Hendriks J, Lauwers P, Suys B, Van Schil P: Orthodeoxia-platypnea syndrome presenting as paradoxical peripheral embolism. Ann Thorac Surg 2008, 85(5): I798-I800.

14. Bouros D, Agouridakis P, Tsatsakis A, Askitopoulou E, Siafakas NM: Orthodeoxia and platypnoea after acute organophosphorus poisoning reversed by CPAP: a newly described cause and review of the literature. Respir Med 1995, 89(9):625-628.

15. Fishman JA: Pneumocystis carinii. In Fishman's Pulmonary Diseases and Disorders 3rd edition. McGraw-Hill; I998:23 I3-233I.

16. Thakur CT, Nanda NC, Malhotra S, St Martin MB, Jamil F, Agrawald $D$, Maheshwari S, Abrams GA, Patel B: Combined interatrial and intrapulmonary shunting in orthodeoxia detected by transoesophageal echocardiography. Echocardiography 2007, 15:101-104.
Publish with Bio Med Central and every scientist can read your work free of charge

"BioMed Central will be the most significant development for disseminating the results of biomedical research in our lifetime. "

Sir Paul Nurse, Cancer Research UK

Your research papers will be:

- available free of charge to the entire biomedical community

- peer reviewed and published immediately upon acceptance

- cited in PubMed and archived on PubMed Central

- yours - you keep the copyright

Submit your manuscript here:

http://www.biomedcentral.com/info/publishing_adv.asp
BioMedcentral 